\title{
CHAPTER 85
}

\section{Seattle Region}

\author{
Kai Nagel
}

\begin{abstract}
A MATSim model of the Seattle region-more precisely the PSRC (Puget Sound Regional Council) area-was developed during K. Nagel's sabbatical stay with the UrbanSim team in Seattle in 2008. The model resulted from a prototypical integration of the UrbanSim software (e.g., Waddell et al., 2003) with MATSim.

The base was an existing PSRC UrbanSim model, which used an established EMME/2 model as a travel model. The investigation centered around how difficult it would be to replace the EMME/2 model with MATSim.

The network was taken, by conversion, from the existing EMME network, resulting in 15478 links and 5025 nodes with attributes length, free speed, and capacity.

Demand was generated as output from UrbanSim. Evidently, the UrbanSim simulation already contained a full synthetic population. The UrbanSim model was also set up with workplace choice, so that each synthetic person with "working" status had a workplace assigned. Since that version of UrbanSim worked on the parcel level, this meant that home-to-work trips could be extracted directly, with coordinates, from the model. As so often for initial MATSim studies, this home-towork demand was then extended to home-work-home plans.

The configuration used standard MATSim scoring parameters: a 7 am workplace opening time and latest work start time of $9 \mathrm{am}$. The iterations were run with re-routing and time mutation enabled until convergence. Since this was an exercise in rapid prototyping, only a $1 \%$ sample of the full synthetic population was used; road network flow and storage capacities were scaled down accordingly. Figure 85.1(a) shows a result. Figure 85.1(b) shows households most affected by a hypothetical closure of the Alaskan Way viaduct, which traverses the Seattle downtown area on the waterfront side to the west.
\end{abstract}

\section{How to cite this book chapter:}

Nagel, K. 2016. Seattle Region. In: Horni, A, Nagel, K and Axhausen, K W. (eds.) The Multi-Agent Transport Simulation MATSim, Pp. 495-496. London: Ubiquity Press. DOI: http://dx.doi.org/10.5334/ baw.85. License: CC-BY 4.0 


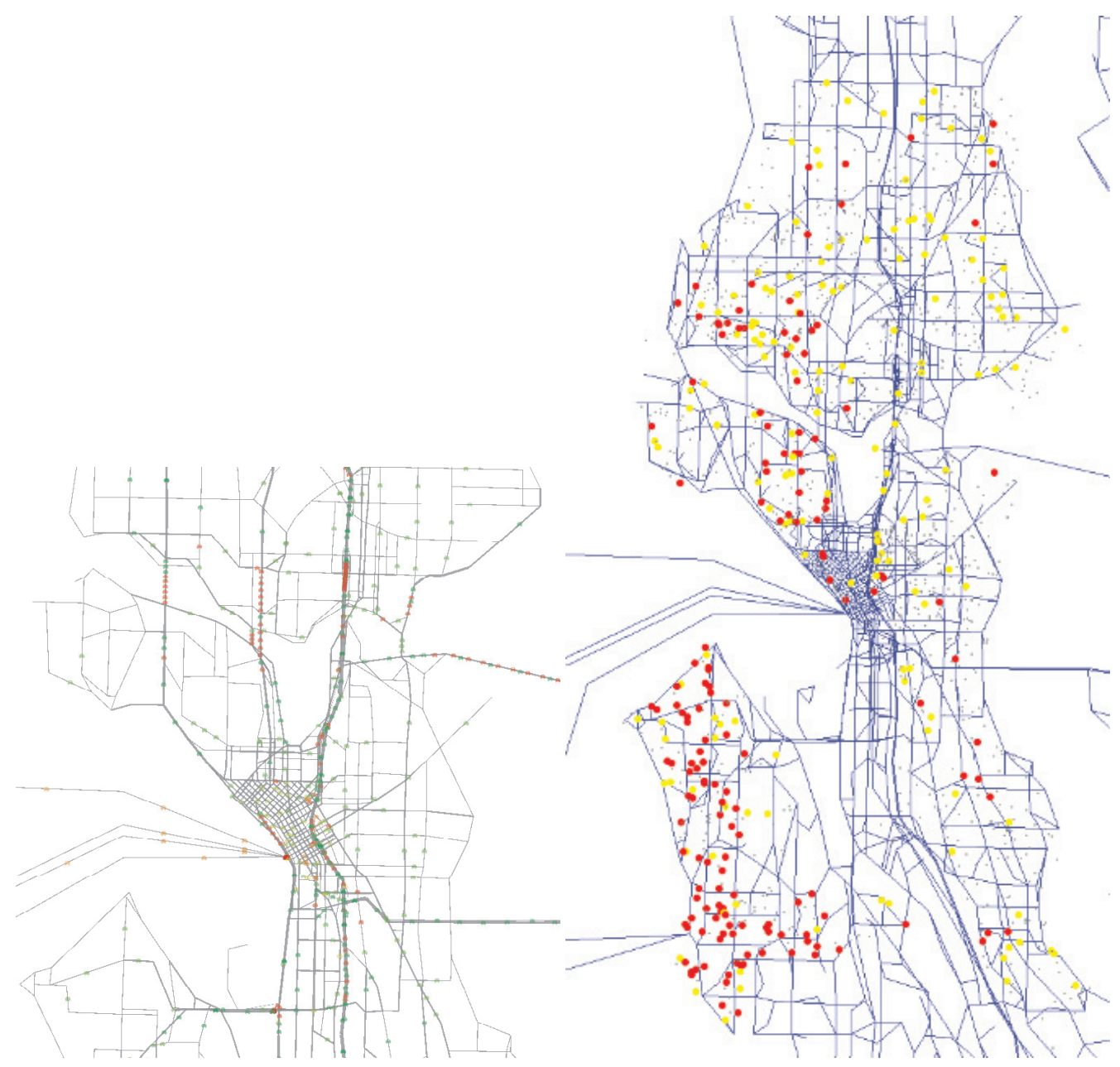

(a) Simulated congestion patterns in Seattle (b) $10 \%$ households most affected by closure of the at 7:30 am so-called Alaskan Way Viaduct (in red)

Figure 85.1: Seattle region scenario. 